\title{
A Case of Pseudoisodicentric Chromosome 18q Detected at Prenatal Diagnosis
}

\author{
Sun Young Cho, M.D. ${ }^{1}$, Gayoung Lim, M.D. ${ }^{1}$, So Young Kim, M.D. ${ }^{1}$, Min Jin Kim, M.D. ${ }^{1}$, Kyung-A Lee, M.D. ${ }^{2}$, \\ Jong Rak Choi, M.D. ${ }^{2}$, Hee Joo Lee, M.D. ${ }^{1}$, Jin-Tae Suh, M.D. ${ }^{1}$, Tae Sung Park, M.D. ${ }^{1}$, and Eui Jung, M.D. ${ }^{3}$ \\ Department of Laboratory Medicine', College of Medicine, Kyung Hee University, Seoul; Department of Laboratory Medicine², \\ Yonsei University College of Medicine, Seoul; Department of Obstetrics and Gynecology ${ }^{3}$, College of Medicine, \\ Kyung Hee University, Seoul, Korea
}

\begin{abstract}
Although trisomy 18 (Edwards' syndrome) or the terminal deletion syndromes of $18 p$ and $18 q$ have been occasionally detected, pseudoisodicentric chromosome 18 is a very rare constitutional chromosomal abnormality. We describe a case of pseudoisodicentric chromosome 18q without mosaicism, which was confirmed from fetal cells in the amniotic fluid used for prenatal diagnosis of multiple congenital anomalies. A 23-yr-old pregnant woman was suspected of having a fetal anomaly at $18^{+3}$ weeks gestation. In sonography, the fetus showed multiple anomalies: bilateral overt ventriculomegaly in the brain, ventricular septal defect and valve anomaly in the heart, bilateral club foot, polydactyly, meningocele, and a single umbilical artery. The pregnancy was terminated and a conventional G-banded chromosome study was performed using amniotic fluid. Twenty metaphase cells among the cultured amniocytes showed a 46,XX,psu idic(18)(q22). Consequently, the fetus had partial trisomy (18pter $\rightarrow$ q22) and partial monosomy (18q22 $\rightarrow$ qter). Both parents were confirmed to have a normal karyotype. (Korean J Lab Med 2010;30:440-3)
\end{abstract}

Key Words : Pseudoisodicentric, Isodicentric, Trisomy 18

\section{서 론}

Pseudoisodicentric (psu idic) 염색체란 두 개의 중심절을 갖고 이 중 한 개의 중심절은 불활성화 되어 있는 같은팔염색체 를 이르는 용어이다[1]. 18번 염색체의 세염색체증(에드워드 증 후군)은 두 번째로 흔한 상염색체 홀배수체(aneuploidy)로서 신생아 8,000명당 하나 정도로 보고되고 있는 반면 18번 염색 체가 psu idic 형태로 나타나는 경우는 매우 드물다[2]. 저자들 은 양수에서 18 번 염색체가 $18 q 22$ 를 절단점으로 하여 쌍중심절 염색체(dicentric chromosome)를 형성함으로서 18번 염색체

Received : January 29, 2010

Manuscript No : KJLM10-035

Revision received: June 9, 2010

Accepted: July 14, 2010

Corresponding author : Eui Jung, M.D.

Department of Obstetrics and Gynecology, College of Medicine, Kyung Hee University, 1 Hoegi-dong, Dongdaemun-gu, Seoul

130-702, Korea

Tel : +82-2-958-8311, Fax : +82-2-958-8328

E-mail : eui2536@hotmail.com

*본 논문은 경희대학교 의과대학병원 임상시험 심사위원회(IRB)의 승인을 받 아 수행된 것임.

ISSN 1598-6535 (C)The Korean Society for Laboratory Medicine
가 부분적 세염색체와 부분적 홑염색체를 나타내고, 표현형적 으로는 다발성 기형을 동반한 증례를 경험하였기에 문헌조사와 함께 이를 보고하는 바이다.

\section{증 례}

임신 18 주 3 일의 23 세 산모가 개인의원에서 시행한 초음파 검사에서 태아의 다발성 기형이 의심되어 본원으로 전원되었 다. 산모는 이전에 건강한 여아를 1 명 출산하였으며 그 외의 인 공유산이나 자연유산의 과거력을 가지고 있지 않았고 염색체 이상이나 기형에 대한 가족력도 없었다. 내원 당시 rapid plasma reagin 검사 음성, $\mathrm{B}$ 형간염 표면 항원 음성, $\mathrm{B}$ 형간염 표면 항체 양성, C형간염항체 음성, HIV 항체 음성이었으며 다른 바 이러스 감염의 임상적 증거도 관찰되지 않았다. 본원에서 재시 행한 초음파 검사에서 태아는 양측 뇌실확장증, 심실사이막결 손, 대동맥판막과 폐동맥판막의 협착증, 양측 곤봉발, 손발가락 과다증, 수막탈출증, 단일배꼽동맥 등의 다발성 선천성 기형 소 견을 보였다(Fig. 1). 산모와 보호자의 동의 하에 양수 검사를 통한 염색체 검사와 임신종결이 시행되었다. 태아는 $190 \mathrm{~g}$ 의 여 

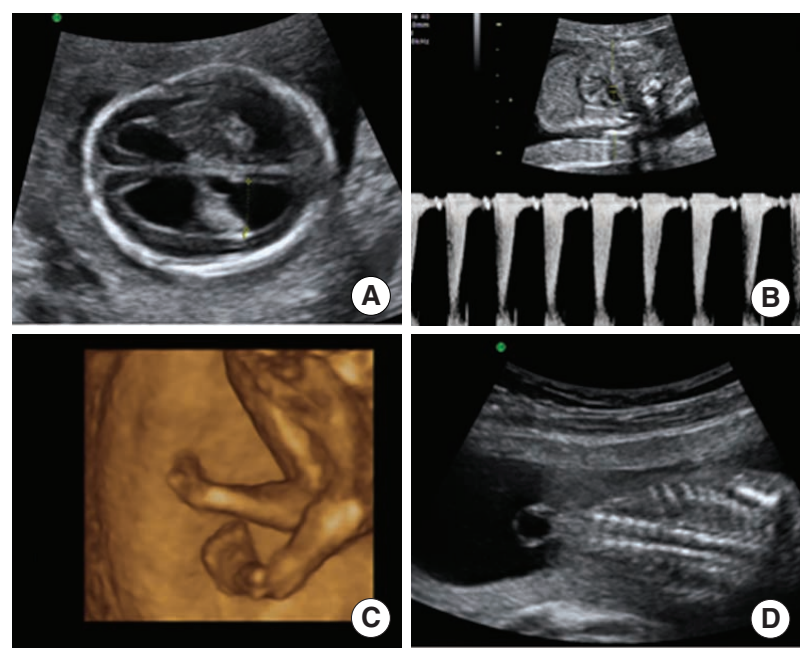

Fig. 1. Prenatal sonographic findings of pseudoisodicentric $18 \mathrm{q}$ at $18^{+3}$ weeks gestation. (A) Transaxial plane of the fetal brain shows bilateral overt ventriculomegaly. (B) Fetal echocardiography shows pulmonary stenosis $(2 \mathrm{~m} / \mathrm{s})$. (C) 3D ultrasonography shows bilateral club foot. (D) Coronal plane of the fetal spine shows meningocele.

아였으며(Fig. 2) 채취된 양수에서 플라스크 배양 후 G-분염법 을 이용한 태아의 핵형분석 결과 2 개의 세포주의 20 개 중기세 포 중 분석된 10 개의 세포에서 모두 pseudoisodicentric chromosome $18 \mathrm{q}$ (46,XX,psu $\operatorname{idic(18)(q22))ㄱㅏ~ㅎㅘㄱㅇㅣㄴㄷㅚㅇㅓㅆㄷㅏ~}$ (Fig. 3). 이 후 말초혈액을 가지고 시행된 부모의 염색체 검사 에서 부모 모두 정상 핵형을 가진 것으로 확인되었다.

\section{고 찰}

쌍중심절염색체(dicentric chromosome)는 중심절의 기원에 따라 첫째, 중심절이 상동염색체로부터 유래하지 않은 heterodicentric 염색체와 둘째, 중심절이 상동염색체로부터 유래 한 homodicentric 염색체, 셋째, 같은 염색체에서 유래된 유전 적으로 동일한 거울상의 중심절을 갖는 isodicentric 염색체로 나눌 수 있다[3-5]. Isodicentric 염색체는 두 개의 상동 염색체 가 동일한 절단점에서 잘려 그 절단점에서 융합된 것으로 정의 되기도 한다[6]. 이러한 isodicentric 염색체에 있는 두 개의 중 심절 중 하나가 기능을 잃고 불활성화되면 염색체는 psu idic 염색체 또는 isopseudodicentric 염색체로 일컬어진다[2, 7]. Psu idic 염색체는 결과적으로 하나의 중심절 만이 일차 협착을 보 여 활성화된 상태이며 이로 인해 비대칭성을 나타내게 된다[1].

18 번 염색체가 관여하는 세포유전학적 이상은 비교적 흔한 편이며 주로 세염색체나 말단 결실의 형태로 나타난다[8]. 이에 비해 상염색체가 쌍중심절염색체 형태로 나타나는 경우는 매우

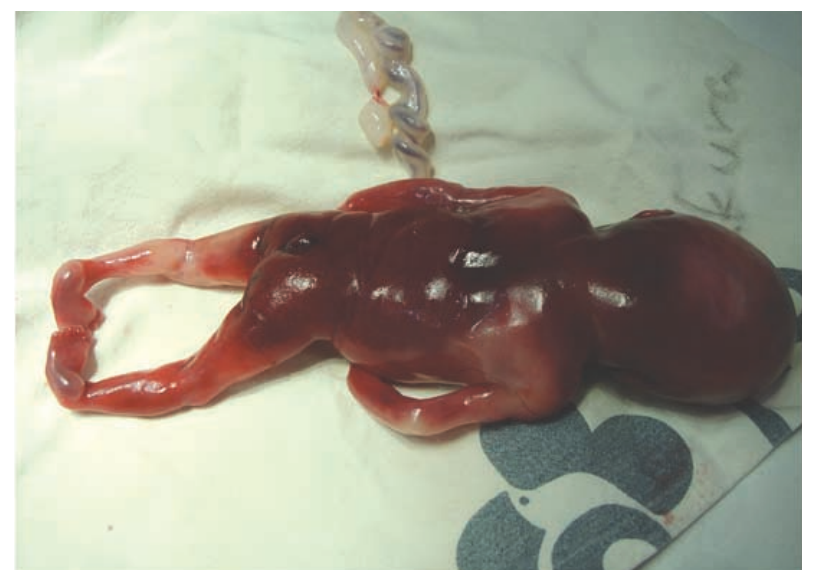

Fig. 2. Photograph of terminated fetus showing bilateral club foot and meningocele.

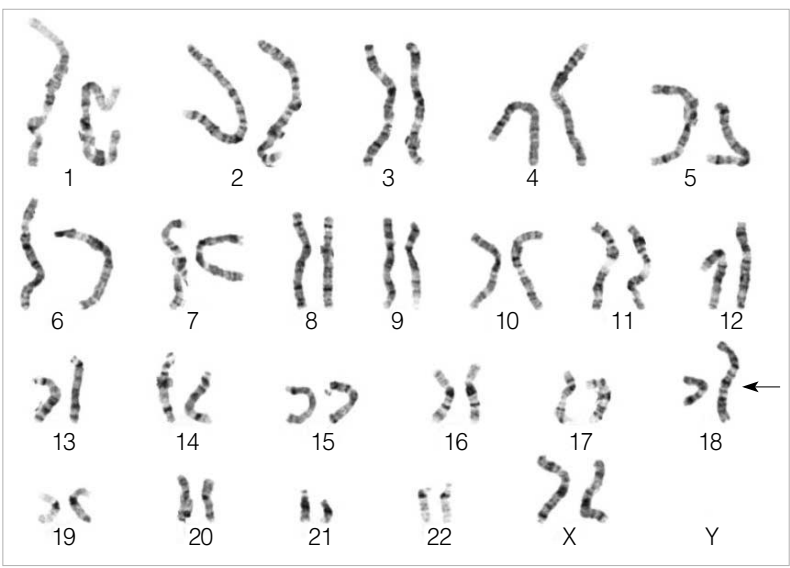

Fig. 3. Karyotype showing pseudoisodicentric chromosome 18 by G-banding analysis. Chromosome 18 shows a breakpoint at $18 q 22$ and has 2 centromeres, the upper one of which has a primary constriction, whereas the lower one lacks a primary constriction.

드문 소견으로, 전통적인 염색체 분석 기법으로는 모든 쌍중심 절을 찾아내기 어렵다는 점도 그 원인 중 하나로 볼 수 있다[9]. 그러므로 $\mathrm{G}$-분염법에 비해 중심절을 확인하는데 유리한 장점 을 가진 $\mathrm{C}-$ 분염법을 적용해 보는 것이 쌍중심절염색체 확인에 도움이 될 수 있겠다.

18 번 염색체가 관련된 쌍중심절 염색체에 대해 이제까지 보 고된 증례들은 10 여 예 정도이며 대부분 경우에서 절단점은 단 완에서 발견되고 모자이시즘을 동반하고 있었다[1, 8]. 본 증례 에서 18 번 염색체는 $18 \mathrm{q} 22$ 를 절단점으로 하여 단완과 장완의 절단점 이상의 부분(18pter $\rightarrow \mathrm{q} 22)$ 은 부분적으로 세염색체가 되는 결과를, 그리고 장완의 절단점 이하의 부분 $(18 q 22 \rightarrow q$ ter $)$ 은 부분적으로 홑염색체가 되는 결과를 나타내었으며 모자이시 
Table 1. Summary of clinical findings for the present case, compared with two other cases of psu idic 18q without mosaicism

\begin{tabular}{|c|c|c|c|c|}
\hline & \multicolumn{4}{|c|}{ Cases of psu idic $18 q$ without mosaicism } \\
\hline & Findings of pure trisomy 18 & 1st case [Meins et al. $\left.{ }^{8}\right]$ & 2nd case [Lin et al. $\left.{ }^{1}\right]$ & Present study [Cho et al.] \\
\hline 1. Karyotype & $47, X X,+18$, or $47, X Y,+18$ & 46,XX,psu dic(18)(q22.1) & 46,XX,psu dic(18) & 46,XX,psu idic(18)(q22) \\
\hline $\begin{array}{l}\text { 2. Intrauterine } \\
\text { growth retardation }\end{array}$ & Detected & Detected & NC & Detected \\
\hline 3. Brain & Ventriculomegaly & Normal & Normal & Ventriculomegaly \\
\hline 4. Face & $\begin{array}{l}\text { Cleft lip and palate, } \\
\text { micrognathia, small and } \\
\text { low-set ears }\end{array}$ & Cleft lip and palate & $\begin{array}{c}\text { Cleft lip and palate, anotia } \\
\text { (Rt. ear), low-set left ear, } \\
\text { micrognathia }\end{array}$ & Normal \\
\hline 5. Neck & No special anomaly & Short & $\mathrm{NC}$ & Normal \\
\hline 6. Thorax & No special anomaly & Narrow & NC & Normal \\
\hline 7. Heart & VSD, ASD, PDA & VSD and ASD & Normal & VSD and valve anomaly \\
\hline 8. Kidney & $\begin{array}{l}\text { Hydronephrosis, } \\
\text { horseshoe kidney }\end{array}$ & Real hypoplasia & Normal & Normal \\
\hline 9. Spinal cord & Neural tube defect & $\mathrm{NC}$ & NC & Meningocele \\
\hline 10. Skin & Cutis laxa & Redundant skin & $\mathrm{NC}$ & Normal \\
\hline 11. Extremities & $\begin{array}{l}\text { Club feet, rocker- } \\
\text { bottom feet }\end{array}$ & $\begin{array}{l}\text { Club foot and hand, } \\
\text { thumb aplasia }\end{array}$ & $\begin{array}{c}\text { Rocker-bottom feet, } \\
\text { abnormal finger* and toe }{ }^{\dagger}\end{array}$ & Club feet and polydactyly \\
\hline 12. Umbilical artery & Single umbilical artery & NC & $\mathrm{NC}$ & Single umbilical artery \\
\hline
\end{tabular}

*Index finger of the left hand crossed over the third and fourth fingers; 'Second toe of the right foot crossed over the third toe.

Abbreviations: NC, not commented upon; VSD, ventricular septal defect; ASD, atrial septal defect; PDA, patent ductus arteriosus.

즘을 동반하지 않아 18 번 염색체가 관여하는 대부분의 psu idic 에 대한 보고들이 모자이시즘을 동반하며 단완에 절단점을 갖 는다는 것과 차이점을 보였다.

Meins 등[8]은 모자이시즘을 동반하지 않는 psu idic $18 \mathrm{q}$ 에 대한 최초의 보고에서 절단점이 단완에 위치한 psu idic 염색체 는 대부분 18 번 세염색체 표현형을 나타내는 반면, 절단점이 장 완에 위치한 psu idic 염색체는 다양한 임상적 양상을 나타내며 이 다양성이 절단점의 위치와 모자이시즘의 정도에 의한다고 설명하였다. 18q21 띠의 복제수가 세 개인 경우 18 번 세염색체 증의 전형적인 표현형에 가깝다는 보고도 있다[10]. Table 1에 서와 같이 본 증례를 Meins 등[8]의 증례(46,XX,psu $\operatorname{dic}(18)$ (q22.1))와 비교해 볼 때 핵형은 유사하나 표현형에 차이를 보이 는 이유로 절단점이 되었던 18q22 주변에 표현형 발현에 영향 을 주는 유전자가 다수 위치할 가능성을 생각해 볼 수 있겠다. 또한 $18 q$ - 증후군의 표현형이 동반되는 현상에 대해 Oudesluijs 등[11]은 $18 q$ 의 결실된 부분이 클수록 $18 q$ - 증후군의 표현형 이 지배적으로 발현된다고 하였다. 본 증례에서는 18 번 세염색 체증에서 흔히 나타나는 심장기형인 심실사이막결손과 사지형 성이상인 곤봉발이 관찰되었고 이는 18 번 염색체의 부분적 세 염색체 효과에 의한 것으로 생각된다. 반면 양안과다격리증 (hypertelorism)과 선천성 이폐쇄증(congenital aural atresia) 등 전형적인 $18 q-$ 증후군의 표현형은 관찰되지 않았다[12]. 기형의 정도는 매우 심하여 여러 주요 기관에서 다발성 기형을
동반하였는데 이는 정상 클론이 공존하지 않았고 18 번 세염색 체증의 표현형 발현에 주요 부분으로 추정되는 $18 \mathrm{q} 21$ 띠가 유 지된 점이 영향을 줄 수 있었을 것으로 생각된다[10, 13]. 향후 18번 세염색체증과 홑염색체증, 그리고 psu idic 18번 염색체 사이의 관계에 대한 규명과 그의 발생기전을 밝히기 위하여 더 많은 임상적 자료의 축적과 분자유전학적 연구가 필요할 것으 로 사료된다.

\section{요 약}

Psu idic 18번 염색체는 18번 세염색체증(Edward 증후군)이 나 18번 장완이나 단완의 부분 결손과는 달리 매우 드물게 보고 된 염색체 이상이다. 저자들은 양수에서 확인된 psu idic 18번 염색체 1 예를 경험하였기에 문헌조사와 함께 이를 보고하는 바 이다. 임신 18 주 3 일의 23 세 산모가 산전진단을 위해 시행한 태 아의 초음파 검사에서 뇌실확장증, 심실사이막결손과 판막 협 착증, 곤봉손발과 다지증, 수막탈출증, 단일배꼽동맥 등의 다발 성 기형을 보였다. 임신종결이 시행되었고 채취된 양수에서 $\mathrm{GTG}-$ 분염법을 이용한 태아의 핵형분석 결과 분석된 20 개의 중기세포에서 psu idic 염색체 18q (46,XX,psu idic(18)(q22)) 가 확인되었다. 본 증례에서 18 번 염색체는 장완의 22 번 띠를 절단점으로 하여 단완과 장완의 절단점 이상의 부분(18pter $\rightarrow$ q22)은 세염색체가 되는 결과를, 그리고 장완의 절단점 이하의 
부분(18q22 $\rightarrow q$ ter)은 홑염색체가 되는 결과를 나타내었다. 이 후 부모의 핵형은 모두 정상으로 확인되었다.

\section{참고문헌}

1. Lin CC, Li YC, Liu PP, Hsieh LJ, Cheng YM, Teng RH, et al. Identification and characterization of a new type of asymmetrical dicentric chromosome derived from a single maternal chromosome 18. Cytogenet Genome Res 2007;119:291-6.

2. Morrissette JJ, Medne L, Bentley T, Owens NL, Geiger E, Pipan M, et al. A patient with mosaic partial trisomy 18 resulting from dicentric chromosome breakage. Am J Med Genet A 2005;137:208-12.

3. Ward BE, Bradley CM, Cooper JB, Robinson A. Homodicentric chromosomes: a distinctive type of dicentric chromosome. J Med Genet 1981;18:54-8.

4. Lemyre E, der Kaloustian VM, Duncan AM. Stable non-Robertsonian dicentric chromosomes: four new cases and a review. J Med Genet 2001;38:76-9.

5. Higgins AW, Gustashaw KM, Willard HF. Engineered human dicentric chromosomes show centromere plasticity. Chromosome Res 2005;13:745-62.

6. Therman E, Trunca C, Kuhn EM, Sarto GE. Dicentric chromosomes and the inactivation of the centromere. Hum Genet 1986;72:191-5.

7. Madan K, Vlasveld L, Barth PG. Ring-18 and isopseudodicentric-18 in the same child: a hypothesis to account for common origin. Ann
Genet 1981;24:12-6.

8. Meins M, Böhm D, Grossmann A, Herting E, Fleckenstein B, Fauth C, et al. First non-mosaic case of isopseudodicentric chromosome 18 (psu idic(18)(pter $\rightarrow$ q22.1::q22.1 $\longrightarrow$ pter) is associated with multiple congenital anomalies reminiscent of trisomy 18 and 18q- syndrome. Am J Med Genet A 2004;127A:58-64.

9. Brandt CA, Djernes B, Strømkjaer H, Petersen MB, Pedersen S, Hindkjaer J, et al. Pseudodicentric chromosome 18 diagnosed by chromosome painting and primed in situ labelling (PRINS). J Med Genet 1994;31:99-102.

10. Matsuoka R, Matsuyama S, Yamamoto Y, Kuroki Y, Matsui I. Trisomy 18q. A case report and review of karyotype-phenotype correlations. Hum Genet 1981;57:78-82.

11. Oudesluijs GG, Hulzebos CV, Sikkema-Raddatz B, Van Essen AJ. Mosaic isodicentric chromosome 18q: sixth report and review. Genet Couns 2006;17:395-400.

12. Feenstra I, Vissers LE, Orsel M, van Kessel AG, Brunner HG, Veltman JA, et al. Genotype-phenotype mapping of chromosome 18q deletions by high-resolution array CGH: an update of the phenotypic map. Am J Med Genet A 2007;143A:1858-67.

13. Wallerstein R, Yu MT, Neu RL, Benn P, Lee Bowen C, Crandall B, et al. Common trisomy mosaicism diagnosed in amniocytes involving chromosomes 13, 18, 20 and 21: karyotype-phenotype correlations. Prenat Diagn 2000;20:103-22. 